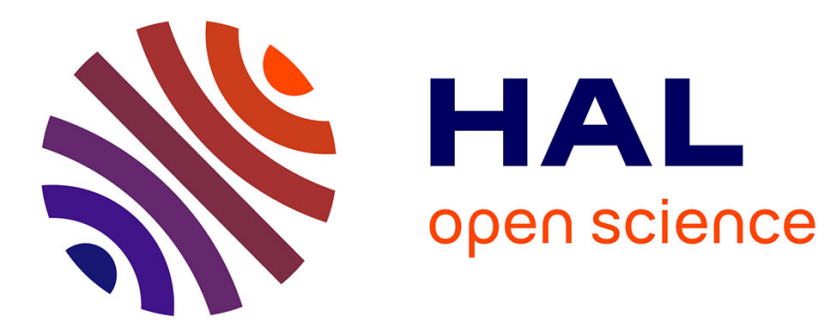

\title{
SECOND HARMONIC GENERATION FROM ORGANIC OPTICAL WAVEGUIDES ON DIFFRACTION GRATINGS
}

\author{
M. Kull, J. Coutaz, R. Meyrueix
}

\section{- To cite this version:}

M. Kull, J. Coutaz, R. Meyrueix. SECOND HARMONIC GENERATION FROM ORGANIC OPTICAL WAVEGUIDES ON DIFFRACTION GRATINGS. Journal de Physique IV Proceedings, 1991, 01 (C7), pp.C7-749-C7-752. 10.1051/jp4:19917201 • jpa-00250882

HAL Id: jpa-00250882

https://hal.science/jpa-00250882

Submitted on 1 Jan 1991

HAL is a multi-disciplinary open access archive for the deposit and dissemination of scientific research documents, whether they are published or not. The documents may come from teaching and research institutions in France or abroad, or from public or private research centers.
L'archive ouverte pluridisciplinaire HAL, est destinée au dépôt et à la diffusion de documents scientifiques de niveau recherche, publiés ou non, émanant des établissements d'enseignement et de recherche français ou étrangers, des laboratoires publics ou privés. 


\title{
SECOND HARMONIC GENERATION FROM ORGANIC OPTICAL WAVEGUIDES ON DIFFRACTION GRATINGS
}

\author{
M. KULL (1) J.L. COUTAZ and R. MEYRUEIX* \\ LEMO-URA CNRS 833, ENSERG, BP. 257, F-38016 Grenoble cedex, France \\ *Flamel Technologies, 33 avenue Dr. Levy, F-69693 Vénissieux cedex, France
}

\begin{abstract}
We present experimental results of second harmonic generation using a waveguide of PUSC deposited on a silver diffraction grating. The reflected second harmonic signal is enhanced at the angles of resonant excitation of the guided modes or of the surface plasmon. At these angles, we observe unexpected minima in the second harmonic signal, when the second harmonic frequency is situated within the absorption range of PUSC.
\end{abstract}

\section{Introduction}

Second Harmonic ( $\mathrm{SH}$ ) Generation is at present intensively studied(1) because many applications would gain in performance by using compact optical sources of blue light. Exemples of such applications are in photocopiers, laser printers, compact disc players for optical storage, etc. A way to reach this wavelength range is to double the frequency of existing laser diodes in the near infrared.

The power of the generated $\mathrm{SH}$ light is proportional to the square of the pump power and to the nonlinear (NL) susceptibility of the material. In order to increase the pump power in the NL material, we use here the optical waveguide configuration. The pump light is coupled into the waveguide by a silver diffraction grating on which an organic film is spin-coated (Fig . 1). At the resonant angles of incidence, a mode of propagation of the structure is excited, leading to an increase of the pump power in the NL layer. The SH light generated in the film is diffracted by the grating, and a strong enhancement, as compared to the bulk case, is expected(2).

Such an enhancement effect has already been reported in the case of bare silver gratings, in which the NL material was either the metal itself $f^{(3)}$, or a surrounding bulk medium ${ }^{(4)}$; for these experiments $(3,4)$, the excited mode of propagation was a surface plasmon (SP). In our case, the NL material is a thin film of polyurethane with side chains (PUSC, synthetized by Flamel Technologies). The modes of the structure are both guided modes and the $\mathrm{SP}$. We present linear and nonlinear characterisation of the device, showing the influence of the resonant excitation of the modes. In addition, we perform the experiment at two different pump wavelengthes. For the first one $(1.32 \mu \mathrm{m})$, the $\mathrm{SH}$ frequency is within the transparency range of the PUSC, but for the second wavelength $(1.06 \mu \mathrm{m})$ the $\mathrm{SH}$ frequency falls in the absorption band of PUSC.

\footnotetext{
(1) Permanent address: Department of Physics II, The Royal Institute of Technology, S-100 44 Stockholm, Sweden
} 


\section{Experiment}

The device in Fig. 1 consists of a sinusoidal grating etched on the surface of a silica substrate. Its periodicity is $d=1.67$ $\mu \mathrm{m}$ and the groove depth is $\delta=80 \mathrm{~nm}$. It is covered by a $0.2 \mu \mathrm{m}$ thick evaporated silver film, and over it, by a $3 \mu \mathrm{m}$ spin-coated layer of PUSC. The PUSC has been poled by an elctrical field applied normal to the surface.

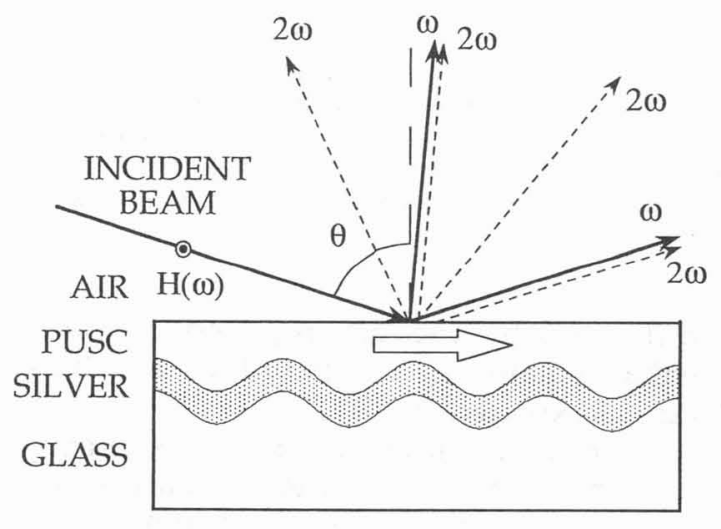

Fig. 1: Scheme of the device.

The NL experiments have been performed with a $\mathrm{Nd}^{3+-}$ YAG laser, which is passively mode-locked at $1 \mathrm{~Hz}$ repetition rate. The pulse duration is $55 \mathrm{ps}$ at $1.06 \mu \mathrm{m}$ and 130 ps at $1.32 \mu \mathrm{m}$. The beam is TM polarized. The SH light generated by the grating is detected by a photomultiplier tube (PMT). The pump beam is rejected from the detected beam by a $4 \mathrm{~mm}$ thick KG5 Schott glass filter and an interference filter (centered at the $\mathrm{SH}$ wavelength). We check that the detected signal comes from $\mathrm{SH}$ generation by verifying, as is usual, the wavelength, the polarization (here TM), the time dependence of the $\mathrm{SH}$ signal and that the $\mathrm{SH}$ power varies as the square of the pump power. This signal is sent through a boxcar to a computer where it is compared with a reference $\mathrm{SH}$ signal simultaneously delivered by a quartz or a
KDP slide, in order to cancel out the power fluctuation of the pump beam. The absolute $\mathrm{SH}$ power is calibrated by comparison with the $\mathrm{SH}$ signal generated by a quartz slab in a Maker fringes experiment. The angular dependence of the SH signal is obtained by placing both the device and the PMT on motorized rotation stages. The angular resolution of the set-up is about 0.1 degree. The linear characteristics in the infrared are measured by replacing the PMT by an InGaAs photodiode.

\section{Results}

The pump light is diffracted by the grating in several orders. When the longitudinal component of the wavevector of an diffracted order is equal to the wavevector, $\mathrm{k}_{\mathrm{g}}$, of a mode of the structure (guided mode or SP), the incident pump light is coupled to the mode following the relation:

$\mathrm{k}_{\mathrm{i} \|}+\mathrm{m} 2 \pi / \mathrm{d}=\mathrm{k}_{\mathrm{g}}$

where $k_{i}$ is the longitudinal incident wavevector $\left(k_{i \| l}=2 \pi / \lambda \sin \theta\right)$ and $m$ is an integer. At the resonant angle which is given by Eq. 1, a part of the pump light is

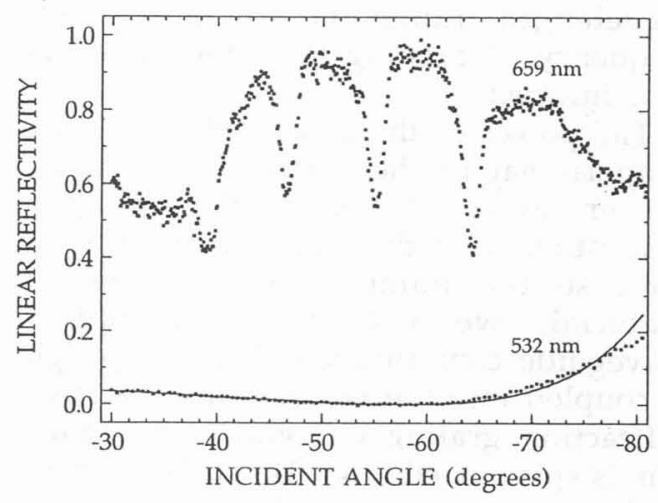

Fig. 2: Linear reflectivity of the device. The upper trace is recorded at $0.66 \mu \mathrm{m}$, the lower at $0.53 \mu \mathrm{m}$. The solid curve is calculated from the Fresnel equation. 
coupled into a guided mode or the SP, leading to a lack of energy in the reflected beam. This is shown in the upper trace of Fig. 2 where we plot the coefficient of reflexion of the grating versus the angle of incidence at the wavelength of $0.66 \mu \mathrm{m}$. On the other hand, at the wavelength of 0.53 $\mu \mathrm{m}$, the same curve does not exhibit angular resonances, because the PUSC film is then strongly absorbing. As the incident light, in that case, cannot reach the metallic grating (the absorption length is $1 \mu \mathrm{m}$ ), the beam is not diffracted and the reflection of the device can simply be fitted by the Fresnel equation (solid curve in Fig . 2).

The upper trace of Fig. 3 shows the reflectivity of the device in the vicinity of the SP excitation at $1.32 \mu \mathrm{m}$. The quite broad angular resonance is due to losses in silver. The specularly reflected $\mathrm{SH}$ power is plotted in the lower trace of Fig. 3. As expected, it reaches a maximum when the

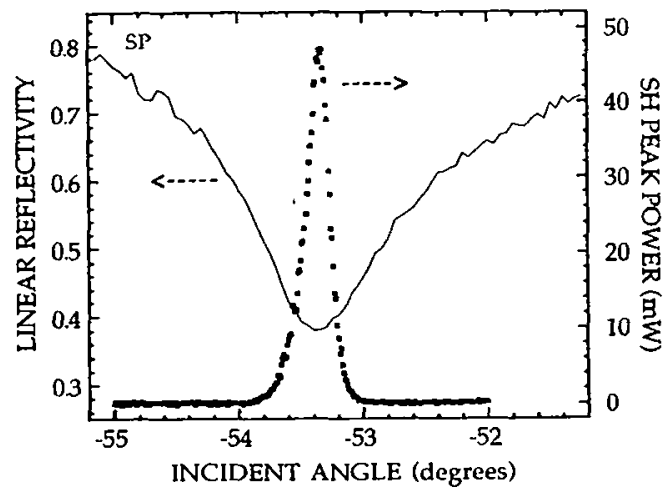

Fig. 3: Linear reflectivity at $1.32 \mu \mathrm{m}$ (upper trace) and $\mathrm{SH}$ reflected power (lower trace) versus the angle of incidence in the vicinity of the SP resonance.

$\mathrm{SP}$ is excited. As compared to the $\mathrm{SH}$ signal level out of resonance, the $\mathrm{SH}$ peak power is enhanced at least two orders of magnitude. The maximum $\mathrm{SH}$ power is 50 $\mathrm{mW}$ for a pump power of $40 \mathrm{~kW}$. A similar feature appears in Fig . 4 where we are concerned with the $\mathrm{TM}_{0}$ guided mode at the pump wavelength. The resonance is now narrow, because the guided mode field propagates mainly in the PUSC layer, and therefore it does not suffer losses in silver.

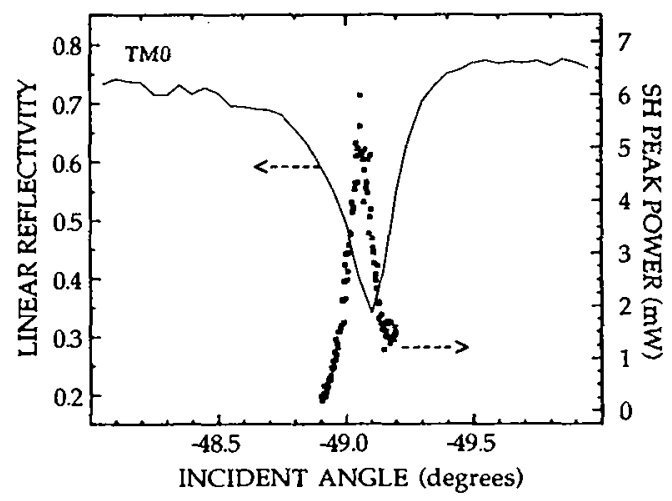

Fig. 4: Linear reflectivity at $1.32 \mu \mathrm{m}$ (upper trace) and $\mathrm{SH}$ reflected power (lower trace) versus the angle of incidence in the vicinity of the $T M_{0}$ guided mode resonance.

At a pump wavelength of $1.06 \mu \mathrm{m}$, the results are very different. Fig. 5 shows the influence of the SP resonance. In the linear reflectivity, we observe the usual black line, but we see a similar minimum also in the $\mathrm{SH}$ reflected power.

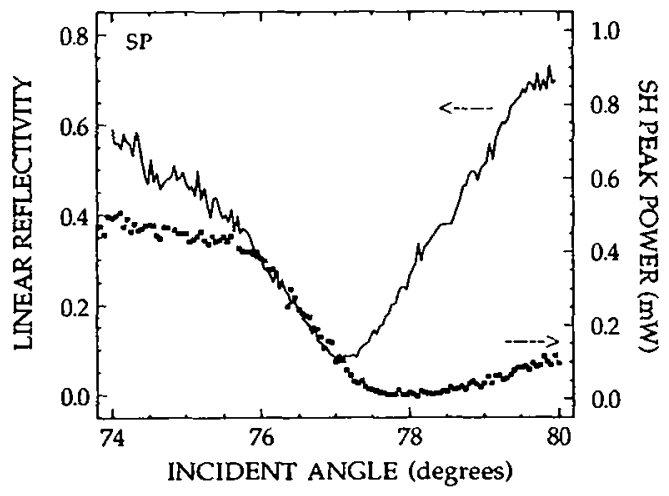

Fig 5: Same as Fig. 3 but recorded at $1.06 \mu \mathrm{m}$ pump wavelength.

The same phenomenon is seen when the $\mathrm{TM}_{0}$ guided mode is excited (Fig. 6). 
This unexpected result is certainly due to the strong absorption of PUSC at the SH wavelength of $0.53 \mu \mathrm{m}$. Numerical studies are under way to explain and modelize the experimental data at both pump frequencies.

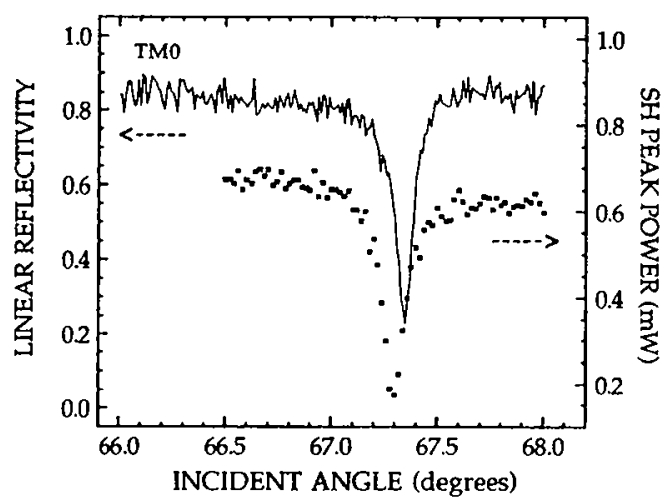

Fig. 6: Same as Fig. 4 but recorded at 1.06 $\mu m$ pump wavelength.

\section{Conclusion}

We have investigated the $\mathrm{SH}$ reflectivity of a PUSC film deposited onto a silver diffraction grating. When the polymer is transparent at the $\mathrm{SH}$ frequency, we measure a strong enhancement of the $\mathrm{SH}$ signal as compared to the bulk case. This enhancement originates from the resonant excitation of a guided mode or of a SP at the pump frequency. However, minima of the $\mathrm{SH}$ signal are observed in the same configuration when the $\mathrm{SH}$ frequency is strongly absorded by the PUSC layer.

Further theoretical studies are planned to understand the physical origin of the minima at $1.06 \mu \mathrm{m}$. As the grating can be utilized to get phase-matching between different modes of propagation of the waveguide, we expect to measure larger values of the $\mathrm{SH}$ generation efficiency in future experiments.

\section{References}

/1 Advance program of CLEO-IQEC, OSA, Baltimore, USA (1991).

/2/ R. Reinisch, M. Nevière, H. Akhouayri, J.L. Coutaz, D. Maystre and E. Pic, Opt. Engineering 27, 961 (1988).

13/ J.L. Coutaz, M. Nevière, E. Pic and R. Reinisch, Phys. Rev. B32, 2227 (1985); for a review, see J.L. Coutaz in "Nonlinear Optics in Solids", edited by $O$. Keller, Springer Verlag, Berlin (1990).

/4/ H. J. Simon, C. Huang, J. C. Quail and Z. Chen, J. Opt. Soc. Am. B38, 7408 (1988);

Z. Chen, D. Cui, H. Lu and Y. Zhou, Opt. Lett. 8,563 (1983). 